\title{
Enhanced secretion of oxytocin from bovine granulosa cells treated with adrenal steroids
}

\author{
M. R. Luck \\ Institute for Hormone \& Fertility Research, Grandweg 64, 2000 Hamburg 54, F.R.G.
}

\begin{abstract}
Summary. Bovine granulosa cells were exposed in vitro to various adrenal steroids (cortisol, cortisone, corticosterone, aldosterone; $1 \mu \mathrm{mol} / 1$ ), in the presence and absence of stimulation by ascorbic acid $(0.5 \mathrm{mmol} / \mathrm{l})$, to determine the possible effects of these hormones on ovarian oxytocin and progesterone secretion. Only cortisol produced a consistent stimulation of the cells; the response was dose-related over the range 0.01 to $1.0 \mu \mathrm{mol} / \mathrm{l}$ and was greatly enhanced in the presence of ascorbate. The secretion of oxytocin was stimulated to a greater extent and with more consistency than was that of progesterone. Although the secretion of oxytocin could be stimulated by cortisol on the day of treatment, the cells also showed a delayed and persistent response to exposure earlier in the culture. It is concluded that cortisol may directly stimulate the secretion of ovarian oxytocin in the cow and that granulosa cells may respond in such a way as to smooth out the effects of short-term fluctuations in cortisol concentration.
\end{abstract}

Keywords: oxytocin; granulosa; adrenal steroids; glucocorticoids; cortisol

\section{Introduction}

Moberg (1987) has reviewed and discussed the interactions which occur at several levels between the adrenal axis and the reproductive system. Compared with interactions at the hypothalamicpituitary level, little is known about the direct effects of adrenocortical hormones on the ovary. In view of the associations between stress conditions, adrenal activity and cyclic ovarian function in several species (Hagino, 1972; Cunningham et al., 1975; Kanchev et al., 1976; Armstrong, 1986) it is of interest to establish the possible sites of hormone action.

Receptors for glucocorticoids have been identified in rat granulosa cells (Schreiber et al., 1982) and appear from in-vitro studies to mediate both inhibitory and stimulatory effects. For example, corticosterone and dexamethasone suppressed plasminogen activator production (Harlow et al., 1987) and at high concentrations reduced the induction of LH receptors and aromatase activity by FSH but enhanced FSH-stimulated progesterone secretion (Hsueh \& Erickson, 1978; Adashi et al., 1981; Schoonmaker \& Erickson, 1983).

Evidence for direct ovarian effects of adrenal steroids in other animals is lacking, although cortisol has been used as a medium supplement during the serum-free culture of cow (Pate $\&$ Condon, 1982) and sow (Baraño \& Hammond, 1985) ovarian cells. Direct perfusion of the cow ovary with cortisol had no effect on ovarian steroid secretion (Wagner et al., 1977) and there appears to be no direct relationship between concentration and the stage of the oestrous cycle (Echternkamp \& Hansel, 1973; Roussel et al., 1983; Spicer \& Zinn, 1987). Nevertheless, in studies on the regulation of oxytocin secretion by cultured bovine granulosa cells (Jungclas \& Luck, 1986), we observed that co-culture with pieces of adrenal tissue could enhance oxytocin but not progesterone secretion. Tissues from both medulla and cortex were stimulatory and subsequent studies suggested that the medullary effect might be due to catecholamines (Luck \& Jungclas, 1987, 1988). In the present experiments the possibility that cortical steroids, at concentrations likely to be 
present in vivo, can stimulate granulosa oxytocin secretion has been investigated. In the culture model used, granulosa cells secrete stimulatable quantities of oxytocin and progesterone by apparently unrelated mechanisms (Luck, 1988); thus it is possible to examine potential stimulants for their separate effects on protein and steroid secretions.

\section{Materials and Methods}

Cell culture. Granulosa cells were obtained from carefully selected follicles of cows not in the follicular phase of the cycle, as previously described (Jungclas \& Luck, 1986; Luck \& Jungclas, 1987, 1988). They were cultured in multiwell plates (Nunclon, Wiesbaden, F.R.G.) at concentrations (estimated from DNA assay; Labarca \& Paigen, 1980) of between 1.4 and $1.8 \times 10^{6}$ cells $/ \mathrm{ml}$, using a mixed medium $(1: 1(\mathrm{v} / \mathrm{v})$ mixture of Dulbecco's modified Eagles Medium and Ham's F12, with glutamine, penicillin, streptomycin and bicarbonate buffer; all from Flow Laboratories, Meckenheim, F.R.G.) supplemented to $10 \%$ volume with fetal calf serum (Gibco, Karlsruhe, F.R.G.). Cultures were continued for 4 days at $37^{\circ} \mathrm{C}$ under $5 \% \mathrm{CO}_{2} / 95 \%$ air. The culture medium was changed daily and samples were held at $-20^{\circ} \mathrm{C}$ to await hormone assay. Four replicate wells per treatment were used.

Hormone assays. Oxytocin was assayed by radioimmunoassay (RIA) as previously described (Jungclas \& Luck, 1986; Luck \& Jungclas, 1987) using an antiserum (242/1, final concentration 1:40000) kindly supplied by Professor A. P. F. Flint (Institute of Zoology, London, U.K.). The working range was $9400 \mathrm{pmol} / 1$. Samples of uncultured medium, with or without ascorbate or treatment steroids, contained no detectable oxytocin. Progesterone was assayed by an RIA kit (RSL, Carson, CA, U.S.A.) as previously described and validated (Webley \& Luck, 1986) with a working range of $0.6-65 \mathrm{nmol} / \mathrm{l}$. Samples were diluted $1: 10,1: 100$ or $1: 1000$ in assay buffer; uncultured treatment media at these concentrations contained no detectable progesterone. Interassay coefficients of variation for the oxytocin and progesterone assays were $11 \%$ and $13 \%$ respectively; intra-assay variation was $<5 \%$ in both cases.

Treatments. Adrenal steroids (cortisol, cortisone, corticosterone and aldosterone; from Sigma, Diesenhofen, F.R.G.) were prepared as stock solutions in ethanol and diluted in culture medium to the required concentration at the start of each experiment. In each experiment the control contained ethanol at an equivalent concentration (final dilution 1:1000). This amount of ethanol had no significant effect on hormone secretion (Fig. 1). Ascorbic acid was used in all experiments at $0.5 \mathrm{mmol} / 1$ and was diluted in culture medium at the start of the experiment (Luck \& Jungclas, 1988). Solutions were sterilized by passage through a $0.2 \mu \mathrm{m}$ membrane filter (Schleicher \& Schuell, Dassel, F.R.G.).

Data presentation. Each of the reported experiments was carried out at least twice and with essentially similar results, despite variations in the absolute levels of hormone secreted by the different batches of cells. As in previous studies with bovine granulosa cells (Jungclas \& Luck, 1986; Luck \& Jungclas, 1987, 1988; Luck, 1988) oxytocin secretion was not detectable on the 1st day of culture and was maximal on the 3 rd day. Accordingly, for experiments

Table 1. Concentrations in medium (mean \pm s.e.m., $n=4$ ) and relative stimulation of oxytocin and progesterone from bovine granulosa cells on the $3 \mathrm{rd}$ day of culture $(48-72 \mathrm{~h}$ ) treated continuously with various adrenal steroids $(1 \mu \mathrm{mol} / \mathrm{l})$, in the absence or presence of ascorbic acid $(0.5 \mathrm{mmol} / \mathrm{l})$

\begin{tabular}{|c|c|c|c|c|c|}
\hline & \multicolumn{2}{|c|}{ Without ascorbate } & \multicolumn{3}{|c|}{ With ascorbate } \\
\hline & Conc. & $\begin{array}{l}\text { Relative to } \\
\text { control without } \\
\text { ascorbate }\end{array}$ & Conc. & $\begin{array}{l}\text { Relative to } \\
\text { control with } \\
\text { ascorbate }\end{array}$ & $\begin{array}{l}\text { Relative to } \\
\text { treatment without } \\
\text { ascorbate }\end{array}$ \\
\hline \multicolumn{6}{|c|}{ Oxytocin (pmol/l $10^{5}$ cells ${ }^{-1}$ day $\left.^{-1}\right)$} \\
\hline Control & $1.76 \pm 0.06$ & - & $3.86 \pm 0.12$ & - & $2 \cdot 2 * * *$ \\
\hline Cortisol & $2.65 \pm 0.10$ & $1 \cdot 5 * * *$ & $6.17 \pm 0.05$ & $1 \cdot 6^{* * *}$ & $2 \cdot 3 * * *$ \\
\hline Cortisone & $2.02 \pm 0.04$ & $1 \cdot 2$ & Not tested & & \\
\hline Corticosterone & $2.25 \pm 0.12$ & $1 \cdot 3$ & $4.83 \pm 0 \cdot 16$ & $1 \cdot 3^{* *}$ & $2 \cdot 1 * * *$ \\
\hline Aldosterone & $2.44 \pm 0.09$ & $1 \cdot 4 * * *$ & $4.69 \pm 0.19$ & $1 \cdot 2^{* *}$ & $1.9 * * *$ \\
\hline \multicolumn{6}{|c|}{ Progesterone ( nmol/l $10^{5}$ cells $^{-1}$ day ${ }^{-1}$ ) } \\
\hline Control & $21 \cdot 4 \pm 1 \cdot 4$ & - & $53 \cdot 7 \pm 2 \cdot 1$ & - & $2 \cdot 5 * * *$ \\
\hline Cortisol & $31 \cdot 2 \pm 3 \cdot 1$ & $1 \cdot 5^{*}$ & $64 \cdot 3 \pm 4 \cdot 9$ & $1 \cdot 2^{* *}$ & $2 \cdot 1 * * *$ \\
\hline Cortisone & $26.6 \pm 1.6$ & $1 \cdot 2$ & Not tested & & \\
\hline Corticosterone & $35.9 \pm 2.4$ & $1 \cdot 7 * * *$ & $66.4 \pm 3.4$ & $1 \cdot 2^{* *}$ & $1 \cdot 9 * * *$ \\
\hline Aldosterone & $34 \cdot 6 \pm 2 \cdot 3$ & $1 \cdot 6^{* *}$ & $58.5 \pm 4.7$ & $1 \cdot 1$ & $1 \cdot 7^{* * *}$ \\
\hline
\end{tabular}

${ }^{*} P<0.05 ;{ }^{* *} P<0.01 ;{ }^{* * *} P<0.001$ (analysis of variance). 

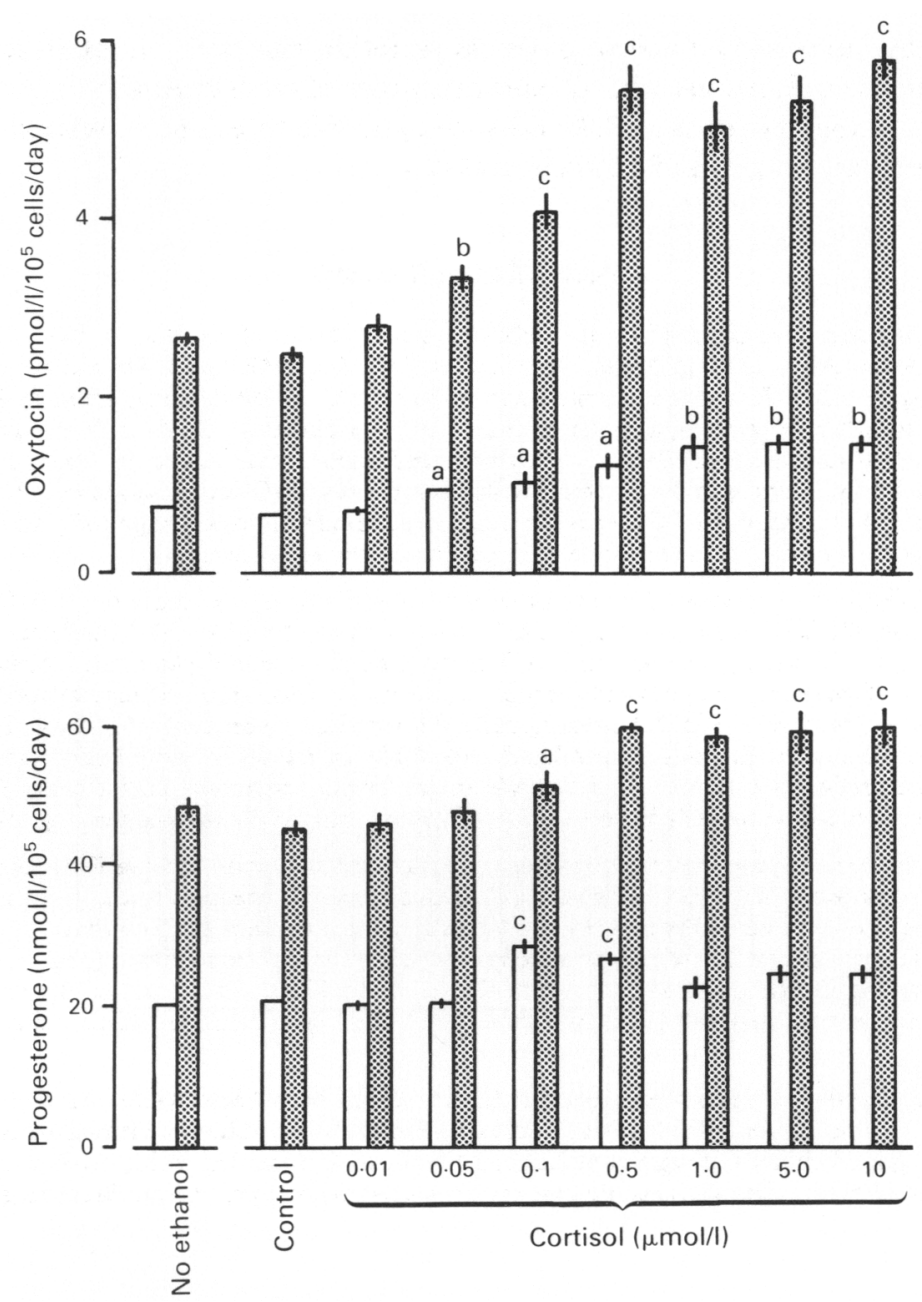

Fig. 1. Effects of increasing concentrations of cortisol on the secretion of oxytocin and progesterone by bovine granulosa cells on the 3rd day of culture in the presence (stippled bars) and absence (open bars) of ascorbic acid $(0.5 \mathrm{mmol} / \mathrm{l})$. Control and cortisol treatments contained ethanol (dilution 1:1000). Values are mean \pm s.e.m. for 4 replicate wells. Error bars are omitted when these are less than the thickness of the line. a, $P<0.05 ; \mathrm{b}, P<0.01 ; \mathrm{c}, P<0.001$, compared with equivalent control value (analysis of variance).

in which cells were continuously exposed to treatment steroids (Table 1; Figs 1 \& 2) results are given for the 3rd day of culture only. Excluding data from other days does not affect the interpretation of the results. Hormone concentrations are expressed as a function of the starting number of cells per culture well. Differences in concentration between treatments were assessed by analysis of variance, with levels of significance determined according to the $t$ distribution.

\section{Results}

\section{Experiment 1}

Four adrenal steroids were screened at a concentration of $1 \mu \mathrm{mol} / 1$ for their ability to influence oxytocin and progesterone secretion, in the presence and absence of ascorbic acid (Table 1). In the absence of ascorbate, oxytocin secretion was significantly stimulated by cortisol and aldosterone 

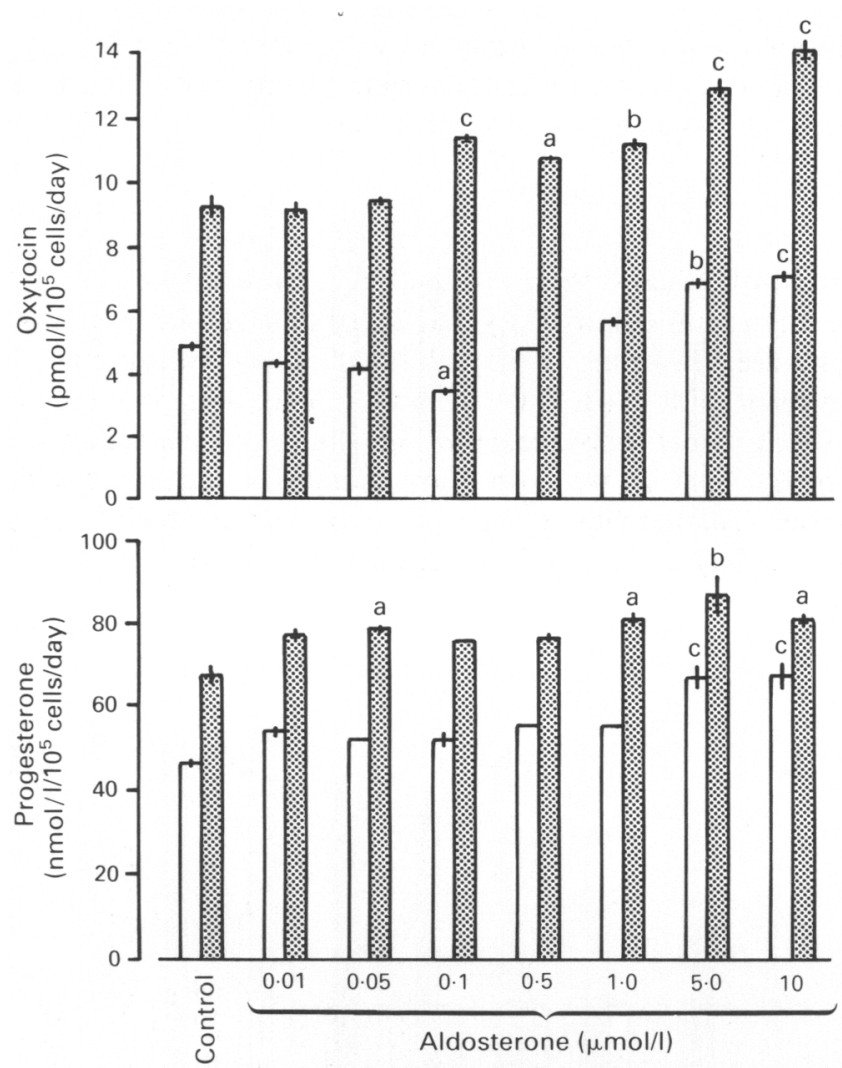

Fig. 2. Effects of increasing concentrations of aldosterone on the secretion of oxytocin and progesterone by bovine granulosa cells on the 3rd day of culture in the presence (stippled bars) and absence (open bars) of ascorbic acid $(0.5 \mathrm{mmol} / \mathrm{l})$. Values are mean \pm s.e.m. for 4 replicate wells. Error bars are omitted when these are less than the thickness of the line. a, $P<0.05 ; \mathrm{b}, P<0.01 ; \mathrm{c}, P<0.001$, compared with equivalent control value (analysis of variance).

whereas cortisol, corticosterone and aldosterone caused a significant increase in progesterone secretion. In the presence of ascorbate, these three steroids also stimulated oxytocin secretion but aldosterone lost its effect on progesterone secretion. The relative stimulation of oxytocin was greatest with cortisol and similar under both conditions. None of the treatments affected cell morphology or proliferation in culture (assessed visually by light microscopy).

\section{Experiment 2}

Cortisol (Fig. 1) caused a significant and dose-dependent increase in the secretion of oxytocin at concentrations between 0.05 and $1.0 \mu \mathrm{mol} / 1$; ascorbate greatly enhanced the level of secretion and magnified the dose effect, slightly sensitizing the cells to lower doses of cortisol $\left(\mathrm{ED}_{50}\right.$ without ascorbate: $0.14 \mu \mathrm{mol} / 1$, with ascorbate: $0 \cdot 10 \mu \mathrm{mol} / \mathrm{l}$, calculated from data in Fig. 1). Progesterone secretion was stimulated by cortisol at a concentration of $0.1 \mu \mathrm{mol} / 1$ but the effects of higher doses were inconsistent in the absence of ascorbate and there was only a limited dose-dependent increase in the presence of ascorbate. The effects of increasing concentrations of aldosterone (Fig. 2) were smaller and inconsistent. The $0.1 \mu \mathrm{mol} / 1$ dose was stimulatory to oxytocin in the presence of ascorbate but mildly suppressive in the absence of ascorbate, and the maximum stimulation at a 
concentration of $10 \mu \mathrm{mol} / 1$ was $1 \cdot 5$-fold compared with more than 2 -fold at the higher concentrations of cortisol. The stimulation of progesterone secretion by aldosterone was also small (maximum 1.5-fold) and inconsistent with respect to dose.

\section{Experiment 3}

The response to cortisol varied with time of culture at which it was given (Fig. 3). On Days 3 and 4 of culture there was a stimulation of oxytocin at the time of treatment whereas on Day 2 there was no immediate response. However, on Days 2, 3 and 4, delayed responses (up to 2-fold stimulation) to earlier treatment with cortisol were seen. A delayed response to treatment on Day 1 appeared despite the lack of detectable secretion on that day. The response of progesterone to timed addition of cortisol also showed (on Days 2 and 3) evidence of a delayed stimulation, although the effects were smaller (up to $1 \cdot 6$-fold) than with oxytocin secretion. There was an immediate stimulation on Day 3 but a slight suppression on Day 4.

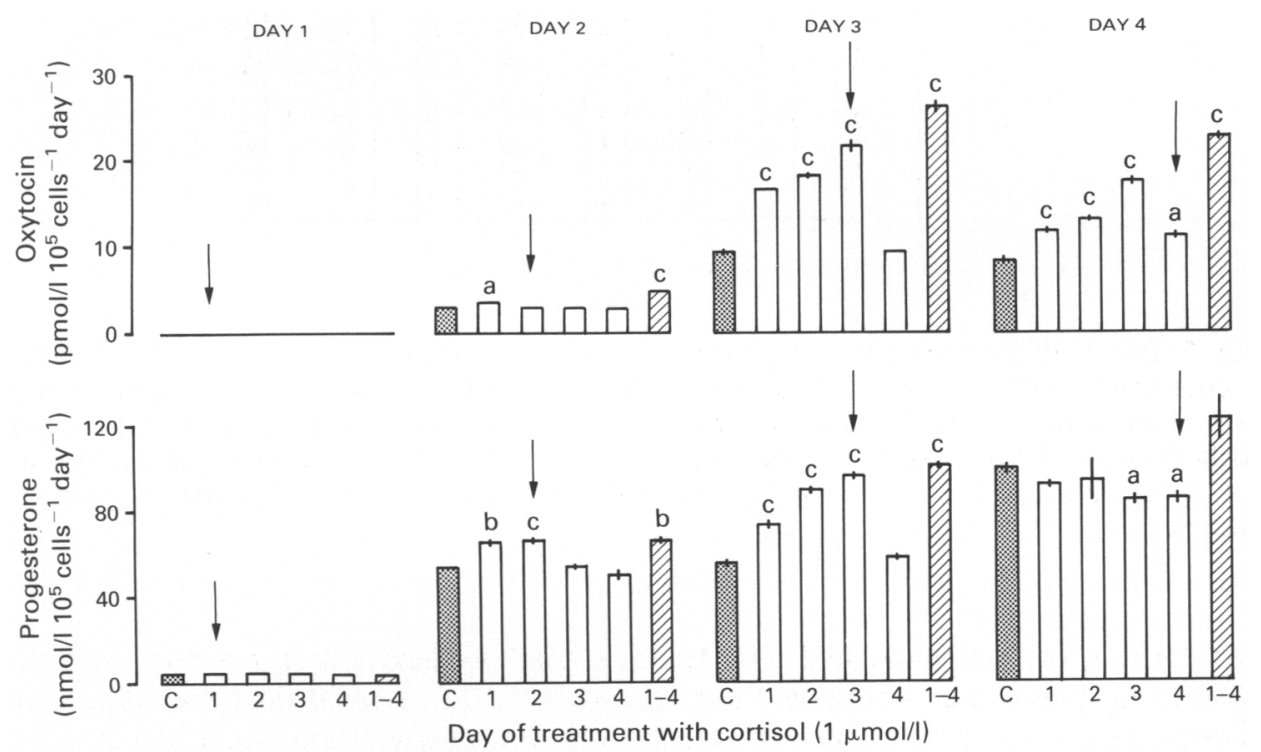

Fig. 3. Oxytocin and progesterone concentrations (mean \pm s.e.m., 4 replicate wells) in medium (changed daily) during a 4-day culture of bovine granulosa cells in the presence of ascorbic acid $(0.5 \mathrm{mmol} / \mathrm{l})$. Cells were treated with cortisol for 1 of the 4 days of culture (indicated by arrow) or continuously (hatched bar). Control cells ( $\mathrm{C}$, stippled bar) received ethanol vehicle. Oxytocin was undetectable $\left(<0.5 \mathrm{pmol} / 1\right.$ per $10^{5}$ cells per day) on Day 1 a a, $P<0.05$; b, $P<0.01 ;$ c,$P<0.001$, compared with untreated cells (analysis of variance). Error bars are omitted when these are less than the thickness of the line.

\section{Discussion}

These experiments provide evidence that adrenal steroids, particularly cortisol, can directly stimulate bovine granulosa cells. Cortisol produced a dose-dependent stimulation of oxytocin at 
concentrations between 0.05 and $1.0 \mu \mathrm{mol} / 1$. This may represent the high physiological range since the concentration of cortical steroids in the plasma of normal cattle appears to be between 0.01 and $0 \cdot 15 \mu \mathrm{mol} / 1$ (Garverick et al., 1971; Swanson et al., 1972; Li \& Wagner, 1983; Roussel et al., 1983), rising to over $0.5 \mu \mathrm{mol} / 1$ during stress (Welsh \& Johnson, 1981; Echternkamp, 1984; Alam \& Dobson, 1986). The exact relationship between the effective dose range and circulating concentrations is uncertain since the majority of the circulating steroid is protein-bound and the relative binding capacity of the $10 \%$ fetal serum present in the culture medium is not known. Nevertheless, these results suggest that endogenous cortisol, at naturally occurring concentrations, may have an enhancing effect on ovarian oxytocin secretion. The small effects of other glucocorticoids, seen at $1 \mu \mathrm{mol} / 1$, suggest that their effects in vivo, if any, would be slight. Similarly, the small and inconsistent effects of aldosterone over a range of concentrations do not suggest an important regulatory role for mineralocorticoids in the ovary.

The effect of cortisol on oxytocin (up to 2-fold stimulation) was modest when compared with that seen, for example, during treatment of granulosa cells with catecholamines (Luck \& Jungclas, 1986, 1987) or FSH (Schams, 1987). Nevertheless, in the present case the stimulation could be distinguished from general culture-enhancement effects, such as increased cell number, since the simultaneous secretion of progesterone was stimulated to a much smaller degree. Furthermore, the relative increase in oxytocin secretion produced by cortisol was unaffected by stimulation of the cells by ascorbate and this was not the case with progesterone secretion. Ascorbate appears to stimulate the secretion of oxytocin and of progesterone through separate mechanisms within the cell (Luck \& Jungclas, 1988; Luck, 1988). Its effect on oxytocin production occurs at a very early stage of culture, probably through an enhancement of precursor processing rather than hormone release (Eipper et al., 1983; Luck \& Jungclas, 1988). The synergistic rather than additive effects of combined ascorbate and cortisol treatment, together with the ability of cortisol to stimulate cells later in culture, suggest that cortisol acts at a relatively late stage in the secretory process.

The effects of the timed additions of cortisol suggest that the stimulation resulting from continuous exposure may have more than one component. The immediate responses to cortisol which occurred were only appreciable later in the culture, whereas there was a delayed and persistent response to treatment from the start of culture. This indicates that cortisol renders some permanent change in the activity of the granulosa cell, its action resembling that of adrenaline in this respect (Luck \& Jungclas, 1988). Presumably, the effect in vivo of such a persistence of response would be to smooth out the effects of short-term fluctuations in cortisol concentration and produce a steady increase in secretion.

The effects of cortisol on the secretion of oxytocin in vivo remain to be seen. Treatment of cows with a synthetic, fluorinated glucocorticoid, betamethasone, can prolong luteal function (Kanchev et al., 1976; Dobson et al., 1987) in the absence of profound changes in progesterone secretion, although whether this is a response to the drug itself or to the resulting adrenal suppression is not yet clear. Since luteal oxytocin is apparently involved the control of luteolysis (Flint \& Sheldrick, 1986) these results may indicate that glucocorticoids have a direct influence on luteal function and that stress-induced changes in adrenal secretion may have direct as well as indirect effects on reproductive cyclicity.

In conclusion, these experiments demonstrate the potential of bovine granulosa cells to respond to physiological concentrations of cortisol. Oxytocin secretion appears to be more sensitive than steroidogenesis to stimulation, and the elevation in secretion may persist well beyond the period of exposure to cortisol.

I thank Monika Münker and Cornelia Praetorius for excellent technical work; Professor F. A. Leidenberger for his interest and generous support; and the Bundesministerium für Forschung und Technologie for financial support (grant 0706506/9). 


\section{References}

Adashi, E.Y., Jones, P.B.C. \& Hsueh, A.J.W. (1981) Synergistic effect of glucocorticoids on the stimulation of progesterone production by follicle-stimulating hormone in cultured rat granulosa cells. Endocrinology 109, 1888-1894.

Alam, M.G.S. \& Dobson, H. (1986) Effects of various veterinary procedures on plasma concentrations of cortisol, luteinising hormone and prostaglandin $F_{2 a}$ metabolite in the cow. Vet. Rec. 118, 7-10.

Armstrong, D.T. (1986) Environmental stress and ovarian function. Biol. Reprod. 34, 29-39.

Baraño, J.L.S. \& Hammond, J.M. (1985) Serum-free medium enhances growth and differentiation of cuitured pig granulosa cells. Endocrinology 116, 51-58.

Cunningham, G.R., Caperton, E.M. \& Goldheizer, J.W. (1975) Antiovulatory activity of synthetic steroids. $J$. clin. Endocr. Metab. 40, 265-267.

Dobson, H., Alam, M.G.S. \& Kanchev, L.N. (1987) Effect of betamethasone treatment on luteal lifespan and the $\mathrm{LH}$ response to $\mathrm{GnRH}$ in dairy cows. $J$. Reprod. Fert. 80, 25-30.

Echternkamp, S.E. (1984) Relationship between LH and cortisol in acutely stressed beef cows. Theriogenology 22, 305-311.

Echternkamp, S.E. \& Hansel, W. (1973) Concurrent changes in bovine plasma hormone levels prior to and during the first postpartum estrous cycle. $J$. Anim. Sci. 37, 1362-1370.

Eipper, B.A., Mains, R.E. \& Glembotski, C.C. (1983) Identification in pituitary tissue of a peptide $\alpha$ amidation activity that acts on glycine-extended peptides and requires molecular oxygen, copper and ascorbic acid. Proc. natn. Acad. Sci. U.S.A. 80, 5144-5148.

Flint, A.P.F. \& Sheldrick, E.L. (1986) Ovarian oxytocin and the maternal recognition of pregnancy. $J$. Reprod. Fert. 76, 831-839.

Garverick, H.A., Erb, R.E., Niswender, G.D., Callahan, C.J. (1971) Reproductive steroids in the bovine. III. Changes during the estrous cycle. J. Anim. Sci. 32, 946-956.

Hagino, N. (1972) The effect of synthetic corticosteroids on ovarian function in the baboon. J. clin. Endocr. Metab. 35, 716-721.

Harlow, C.R., Coombs, J.J., Hodges, J.K. \& Jenkins, N. (1987) Modulation of plasminogen activation by glucocorticoid hormones in the rat granulosa cell. $J$. Endocr. 114, 207-212.

Hsueh, A.J. \& Erickson, G.F. (1978) Glucocorticoid inhibition of FSH-induced estrogen production in cultured rat granulosa cells. Steroids 32, 639-648.

Jungclas, B. \& Luck, M.R. (1986) Evidence for granulosatheca interaction in the secretion of oxytocin by bovine ovarian tissue. J. Endocr. 109, RI-R4.

Kanchev, L.N., Dobson, H., Ward, W.R. \& Fitzpatrick, R.J. (1976) Concentrations of steroids in bovine peripheral plasma during the oestrous cycle and the effect of betamethasone treatment. J. Reprod. Fert. 48, 341-345.
Labarca, C. \& Paigen, K. (1980) A simple, rapid and sensitive DNA procedure. Analyt. Biochem. 102, $344-352$.

Li, P.S. \& Wagner, W.C. (1983) Effects of hyperadrenal states on luteinizing hormone in cattle. Biol. Reprod. 29, 11-24.

Luck, M.R. (1988) Ovarian oxytocin and progesterone are secreted independently of one another. Molec. cell. Endocr. 56, 149-155.

Luck, M.R. \& Jungclas, B. (1987) Catecholamines and ascorbic acid as stimulators of bovine ovarian oxytocin secretion. J. Endocr. 114, 423-430.

Luck, M.R. \& Jungclas, B. (1988) The time course of oxytocin secretion from cultured bovine granulosa cells, stimulated by ascorbate and catecholamines. J. Endocr. 116, 247-258.

Moberg, G.P. (1987) Influence of the adrenal axis upon the gonads. Oxford Rev. Reprod. Biol. 9, 456-496.

Pate, J.L. \& Condon, W.A. (1982) Effects of serum and lipoproteins on steroidogenesis in cultured bovine granulosa cells. Molec. cell. Endocr. 28, 551-562.

Roussel, J.D., Clement, T.J., Aranas, T.J. \& Seybt, S.H. (1983) Changes in circulating plasma levels of cortisol in lactating and non-lactating dairy cattle during the estrous cycle. Theriogenology 19, 535-539.

Schams, D. (1987) Luteal peptides and intercellular communication. J. Reprod. Fert., Suppl. 34, 87-99.

Schoonmaker, J.N. \& Erickson, G.F. (1983) Glucocorticoid modulation of follicle-stimulating hormonemediated granulosa cell differentiation. Endocrinology $113,1356-1363$.

Schreiber, J.R., Nakamura, K. \& Erickson, G.F. (1982) Rat ovary glucocorticoid receptor: identification and characterization. Steroids 39, 569-584.

Spicer, L.J. \& Zinn, S.A. (1987) Relationship between concentrations of cortisol in ovarian follicular fluid and various biochemical markers of follicular differentiation in cyclic and anovulatory cattle. J. Reprod. Fert. 81, 221-226.

Swanson, L.V., Hafs, H.D. \& Morrow, D.A. (1972) Ovarian characteristics and serum LH, prolactin, progesterone, and glucocorticoid from first estrus to breeding size in Holstein heifers. J. Anim. Sci. 34, 284-293.

Wagner, W.C., Strohbehn, R.E. \& Larson, P.A. (1977) Effect of local or parenteral application of ACTH or hydrocortisone on bovine corpus luteum function. Acta endocr., Copenh. 85, 158-168.

Webley, G.E. \& Luck, M.R. (1986) Melatonin directly stimulates the secretion of progesterone by human and bovine granulosa cells in vitro. J. Reprod. Fert. 78, $711-717$.

Welsh, T.H. \& Johnson, B.H. (1981) Stress induced alterations in secretion of corticosteroids, progesterone, luteinizing hormone and testosterone in bulls. Endocrinology 109, 185-190.

Received 19 January 1988 